\title{
Implementation intentions and test anxiety: Shielding academic performance from distraction
}

\author{
Elizabeth J. Parks-Stamm ${ }^{a, *}$, Peter M. Gollwitzer ${ }^{a, b}$, Gabriele Oettingen ${ }^{a, c}$ \\ New York University, Psychology Department, 6 Wishington Pl, 7th Fioor, New York, NY 10003, USA \\ - University of Konstanz, Getmany \\ "University of Homburg. Germany
}

Keywords:

Implementation intentions

Distraction

Test anxiefy

Plans

Goal shielding

\begin{abstract}
A B S T R A C T
College students whose test anxiety was measured completed a working memory-intensive math exam with televised distractions. Students were provided with implementation intentions (if-then plans; Gollwitzer. 1999) designed to either help them ignore the distractions (i.e., temptation-inhibiting plans) or focus more intenty on the math exam (i.e., task-facilitating plans). Regression analyses showed that as test anxiety increased, the effectiveness of temptation-inhibiting implementation intentions increased, whereas taskfacilitating implementation intentions increasingly harmed performance as test anxiety increased. In addition, the consequences of these plans differed significantly for those high in test anxiety. Implications for effective self-regulation by test-anxious students are discussed.
\end{abstract}

\section{Self-regulation and test anxiety: shielding academic performance from distraction}

One major obstacle to academic achievement is the challenge of shielding academic goal pursuit from unwanted distractions. Because academic success requires continuous striving in the face of distractions (e.g. paying attention in class, completing homework assignments, studying, concentrating during a test), there are numerous opportunities for unwanted distractions to impede academic goal attainment. Two approaches have been suggested to shield goal striving from distraction: ignoring the distraction (i.e., by forming temptation-inhibiting plans) and amplifying the desired behavior (i.e., by forming task-facilitating plans). Which of these plans can we recommend to students to shield academic goal striving from unwanted distractions?

Patterson and Mischel (1975, 1976; Mischel \& Patterson, 1976) first addressed this question by exploring resistance to distraction in young children. They launched their program of research by investigating whether providing children with plans incompatible with succumbing to distraction could help them complete an assigned task (Patterson \& Mischel, 1975). Children between the ages of 3 and 6 were asked to work on a boring pegboard task in the presence of a powerful temptation named Mr. Clownbox. This box-that could light. up and talk-would intermittently tempt the children to play with him or look at his toys displayed through a window mounted at his

\footnotetext{
* Comesponding author. Tel $:+12129987907 ;$ fax: + 12129954966. E-moil adtress: ejp234@nyuedu (E.J. Parks-Stamm)
}

chest. The experimenter then left the room, allowing the child fifteen minutes to work on the pegboard task in the presence of an active $\mathrm{Mr}$. Clownbox. A hidden video camera revealed that children who were given a plan for how to resist Mr. Clownbox spent significantly more time working on the task than children without a plan.

Using the same experimental procedure, Patterson and Mischel (1976) then systematically varied the content of the plans to resist distraction. Each child was given either a temptation-inhibiting plan (e.g.. "I'm not going to look at Mr. Clownbox") or a task-facilitating plan (e.g., "I'm going to look at my work") to accomplish the pegboard task. Patterson and Mischel found that temptation-inhibiting plans, but not task-facilitating plans, helped children to escape distraction more effectively than the children who were not given a plan, especially when that plan was well-elaborated (i.e., where a scripted response to Mr. Clown Box was provided; Mischel \& Patterson, 1976).

Research by Gollwitzer and colleagues on implementation intentions sheds light on the mechanisms underlying Mischel and Patterson's (1976) findings favoring elaborated (i.e., scripted) plans. Gollwitzer (1993, 1999) proposed that individuals can improve rates of goal attainment by planning out their goal striving in the form of implementation intentions. Implementation intentions are highly elaborated if-then plans that include both a relevant situational cue (e.g., if I hear a distraction) and a concrete response (e.g., then I will ignore it). Implementation intentions are proposed to aid goal striving by increasing the accessibility of the situational cue specified in the ifcomponent and by automating the response specified in the thencomponent (Gollwitzer, 1999; Parks-Stamm, Gollwitzer, \& Oettingen, 2007). 
Implementation intentions have been utilized successfully in academic goal striving (see Gollwitzer $\&$ Sheeran, 2006 for a review) For example, Brandstäter, Lengfelder \& Gollwitzer (2001) challenged participants to complete a curriculum vitae by the end of the day. They found that whereas none of the students who had formed a mere goal completed this task by the deadline, $60 \%$ of the participants who had formed an implementation intention had done so. In a separate study on time spent studying for exams, the use of implementation intentions significantly predicted studving time above the predictive strength of students' intentions to study (Sheeran, Webb, \& Gollwitzer, 2005). As stated above, implementation intentions are proposed to make these gains in goal attainment by automating the initiation of the planned response upon contact with the specified cue, thereby making the goaldirected response more efficient than striving without implementation intentions (i.e. individuals with implementation intentions require less cognitive resources to complete the same task). Indeed, research by Webb and Sheeran (2003) has shown that using implementation intentions actually conserves working memory resources. Participants who used implementation intentions in a first working memory task (i.e, a Stroop test) showed no subsequent deficits in a second working memory task of tracing puzzles.

Because of the efficiency of striving with implementation intentions, using implementation intentions to combat distraction should be particularly useful for students as test anxiery increases. Tes anxiety is a form of evaluation anxiety, meaning that central to its initiation is an evaluative or ego-threatening testing situation (Lazarus, 1999). Test anxiety expresses itself in maladaptive cognitive responses (such as worry cognitions and test-irrelevant thinking) to academic stressors (Sarason, 1984; Steele, 1997; Wine, 1971). These maladaptive responses to high-pressure situations lead to decrements in performance called "choking under pressure" (Batmeister, 1984), because of the decreased working memory capacity left over to attend to the task (Beilock \& Carr, 2005; Kane \& Engle, 2000).

Working memory has been implicated as central to the performance costs in performance pressure (Beilock 8 Carr, 2005) and test anxiety (Ashcraft \& Kirk, 2001). The maladaptive responses of testanxious students (i.e., worries, task-irrelevant thoughts) compete for the working memory resources needed to successfully perform their academic task. Distractions are therefore more disruptive for testanxious students with a reduced availability of cognitive resources than for less anxious students. For example, highly test-anxious participants in a high-stress situation show greater attention to distracting cognitions than those low in test anxiety or those in a less stressful situation (Deffenbacher, 1980); they also show more off-task glancing than those low in test anxiety (Nottelmann \& Hill, 1977). Encountering distractions futther depletes working memory resources, leading to greater costs in task performance.

Thus, a self-regulation strategy that has been proven to reduce working memory demands such as implementation intentions should be particularly useful for those with high test anxiety. Secondly, because of the stress-inducing nature of academic tasks (i.e., tests or exams), it seems the content of one's plan should focus attention away from the task. Temptation-inhibiting implementation intentions (e.g." "If I encounter a distraction, then I will ignore it!") draw attention away from the source of stress (e.g., the test), whereas taskfacilitating implementation intentions (e.g. "If I encounter a distraction, then I will focus harder on the test!") may further exacerbate the stress and pressure associated with the test-taking situation.

In line with this reasoning, Gollwitzer and Schaal (1998) hypothesized that when performance pressure is already high, taskfacilitating plans (i.e., to work harder on the focal task) may increase the pressure to stucced to an unmanageable level, thereby depleting working memory resources needed to successfully complete the task In two studies, they manipulated performance pressure, and found that the task-facilitating implementation intentions did not improve performance when motivation was high, thereby replicating the findings of Patterson and Mischel (1976). Only the temptationinhibiting implementation intentions improved performance in the high performance pressure condition. As both test anxiely and performance pressure have been shown to increase working memory demands, this provides some indirect evidence for our hypothesis that highly test-anxious students should benefit from implementation intentions that focus on ignoring distraction rather than on working harder on the task at hand.

In the present experimentah study, we explore this question in at academic setting. College students completed a working memoryintensive math exam while an interesting televised distraction was presented at unexpected intervals. Structured plans in the form of implementation intentions were given to the participants to help them combat this distraction. We hypothesized that temptationinhibiting implementation intentions would be increasingly effective for protecting academic performance from distraction as test anxiety increased. Further, we hypothesized that task-facilitating implementation intentions (i.e., to focus harder on the math exam when distracted) would be increasingly detrimental for performance as test anxiety increased.

\section{Method}

\subsection{Participants}

Fifty-one undergraduates from New York University volunteered to participate in exchange for partial course credit. Test anxiety was measured as a continuous variable, and participants were randomly assigned to task-facilitating or temptation-inhibiting plan condition. One outlier (outside 3 SDs) was excluded.

\subsection{Measures}

Test anxiety was measured at the beginning of the experiment, before the experimental task was introduced, using the short form of the Test Anxiety Inventory (Spielberger et al., 1980; Taylor \& Deanne, 2002). This 5-item questionnaire includes items from both the Worry and Emotionality subscales of the TAl; sample items are "During examinations I get so nervous that I forget facts I really know" and "During tests I feel very tense." Participants rated how often they felt this way "just prior to the final examination in an important course" $(1$ - almost never, 4 - almost always). Test anxiety scores were computed by summing the five items, with total scores ranging from 5 to $18(\alpha=83)$. Participants then completed a working memoryintensive math exam as televised distractions appeared in a separate window on the same computer screen.

\subsection{Procedure}

As in Gollwitzer and Schal (1998), the math exam consisted of problems from Düker's Concentration Achievement Test. In this test, two rows of three numbers are presented, with addition and subtraction signs between them. One must first calculate the result of each row, and if the result of the top row is greater, the bottom is then subtracted from the top. However, if the result of the bottom row is greater, then the two numbers are added. Thus, the task depends heavily on working memory, as it requires mental addition and subtraction, as well as the maintenance and manipulation of temporary information during ongoing processing (Füst \& Hitch, 2000). Participants were given $3 \mathrm{~min}$ of practice time in which they could ask questions to ensure they understood the instructions.

All participants were told that their goal for the task should be to not allow oneself to get distracted and to complete as many math problems as possible in the time allotted. All participants were given the goal to not get distracted by the commercials. All participants were then told, "In order to help you achieve this, pay careful 
attention to the following technique that you can repeat to yourself during the task." Participants in the task-facilitating group were asked to adopt the following if-then plan: "If I hear or see the commercials, then I will increase ny efforts on the math task!" Participants in the temptation-inhibiting group were given the following if-then plan: "If I hear or see the commercials, then I will ignore them!"

Both the math exam and distraction were presented on the same computer screen. As the math questions appeared at the bottom left of the screen, distracting commercials appeared in a window in the top right corner. Television commercial clips from non-US markets were selected from the Cannes Lions 2004 Winners, to ensure they were novel and maximally entertaining to our American participants. Participants were given $15 \mathrm{~min}$ to work on the math exam, with 6 separate distraction phases of $75 \mathrm{~s}$ each, totalling $7.5 \mathrm{~min}$ of distraction.

\section{Results}

Because the instructions were focused on completing as many math problems as possible, rather than accuracy, the number of problems completed during the 15 min served as our primary dependent variable (see also Cool et al., 1994; Collwitzer \& Schal, 1998). All variables were centered around the mean. First, the number of items completed was regressed on plan condition and test anxiety score, with the interaction between these terms added as a second step. The predicted interaction was the only significant effect, $\beta=38, t(49)=2.77, p<01$. The obtained interaction confirmed that the effectiveness of temptation-inhibiting implementation intentions increased as test anxiety increased, whereas the task-facilitating implementation intentions decreased in their efficacy as test anxiety increased. See Fig. 1. Because the number of problems completed was highly correlated with the number of problems solved correctly, $r=.94, p<.001$, we repeated this regression controlling for correct responses. Including cortect responses in the first step, $\beta=.90, t(49)=19.22, p<.001$, strengthened this interaction, $\beta=16, t(49)=3.39, p=.001$. This model accounted for over $90 \%$ of the variance in problems completed, $p<.001$.

As this suggests different outcomes for students high in test anxiety and those low in test anxiety, students were divided into two groups based on a median split of test anxiety scores. As a result of the median split, those in the low anxiety condition $(M=8.04, S D=1.47)$ were significantly different in test anxiety from those itr the high anxiety condition $(M=13.48, S D=2.25), t(48)=10.33, p>.001$. An analysis of variance for a 2 (test anxiety: low versus high) $\times 2$ (plan: task-facilitating versus. temptation-inhibiting) factorial design was then conducted on problems completed. The interaction between type of plan and test anxiety was significant, $F(1,46)=10.49$. $p=.002$. The number of items correctly solved also showed this interaction, $F(1,46)=3.95, p=.05$. See Fig. 2 .

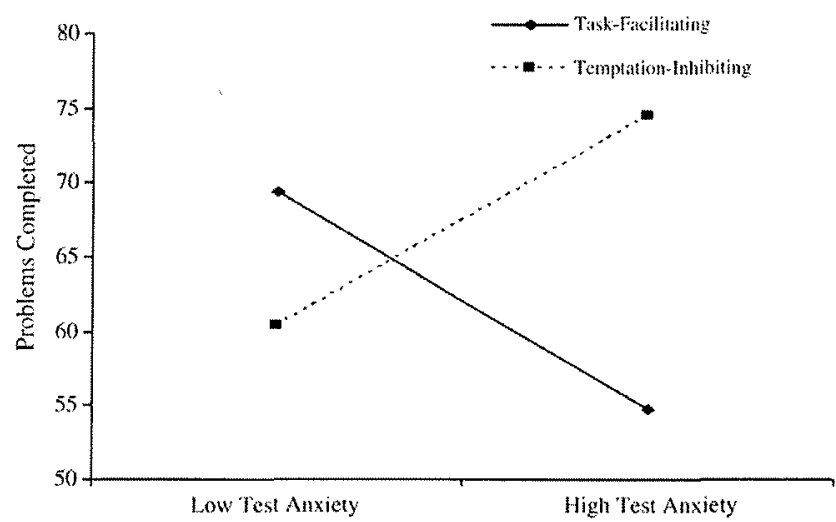

Fig. 1. Problems completed as a function of planning condition and test anxiety. Means are plotted $+1 S D$ from the mean.

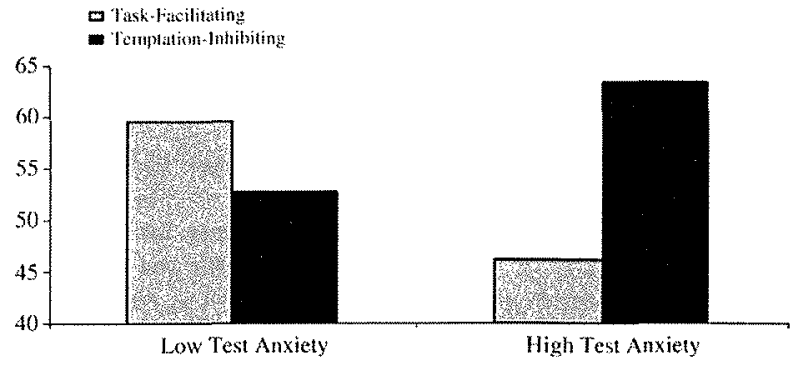

Fig. 2. Number of correct responses as a function of planning condition and median split of test anxiety.

Follow-up analyses of the effects of plan condition within each anxiety group were then performed to further examine this interaction. Among students high in test anxiety, students with temptation-inhibiting plans $(M=77.67, S D=11.59)$ completed significantly more problems than students with task-facilitating plans $(M=54.36, S D=15.71), t(21)=3.82, p=.001$, and correctly answered significantly more problems as well, $t(21)=2.24, p<.05$. As expected, temptation-inhibiting implementation intentions were more effective than task-facilitating implementation intentions for students high in test anxiety. In the low anxiety group, however, no effect of plan was observed in items completed, $t(25)=1.23, p=.23$. or correctly solved, $t(25)=.76, p=.45$. Paired comparisons between the high and low test anxiety participants within the task-facilitating implementation intention condition provided further evidence that task-facilitating plans are particularly problematic for those high in test anxiety. High anxiety was detrimental to students' performance only when task-facilitating implementation intentions were employed; task-facilitating implementation intentions led to significantly poorer performances in terms of problems completed when test anxiety was high $(M=54.36, S D=15.71)$ than when test anxiety was low $(M=68.69, S D=16.73), t(25)=2.30, p=.03$; this was also the case for the number of items correctly solved, $t(25)=1.79, p<.09$. Those with high anxiety actually completed more problems than those low in test anxiety when a temptation-inhibiting implementation intention was employed, $t(21)=2.26, p<.05$, although this difference was not significant for problems correctly solved, $t(21)=$ $1.10, p=.29$.

\section{Discussion}

The present study investigated the best way to shield academic goal striving from unwanted distractions with implementation intentions. An interaction between plan type and test anxiety was found. As test anxiety increased, temptation-inhibiting implementation intentions increasingly benefited performance, whereas taskfacilitating implementation intentions increasingly impaired performance. Indeed, task-facilitating implementation intentions led to a significant cost in performance for those high in test anxiety relative to the less test-anxious students; an ironic consequence of a plan labeled "task-facilitating." This suggests that students who experience test anxiety benefit from forming implementation intentions to ignore distractions rather than on intensifying their efforts on the ongoing test, both in terms of their ability to complete the task at hand (i.e., problems completed) and achievement (i.e., items correctly solved).

The relevance of this research is not limited to students who are clinically diagnosed with test anxiety; the range of test anxiety scores represented an indiscriminate sample of our university student participant population. Indeed, we strove for realism and relevance in all aspects of our study design. Past research has shown that background television impedes both homework performance (Pool, Koolstra, \& Van der Voort, 2003) and time to complete homework assignments (Cool et al., 1994). In spite of these known costs, a recent 
national survey reported that $51 \%$ of secondary students watch television while completing their homework (Markow, Kim, \& Liebman, 2007). Distraction is a real obstacle to students' academic achievement, and the current study provides clear recommendations for students confronted with distractions while completing an academic task.

The current research has important implications for how people should plan out their goal striving, as it highlights the necessity of tailoring the content of plans to the individual. It is clear from the robust effects of implementation intentions that the structure of one's plans (i.e., the if-then structure) is important (Gollwitzer \& Sheeran, 2006). However, the current findings underscore the imporiance of plan content as well. Individuals who reported experiencing test anxiety performed significantly worse when they formed an implementation intention focused on improving task performance as opposed to inhibiting the distraction. However, the two plans did not significantly differ for those low in test anxiery. Taking into account one's proclivity towards test anxiety is thus very important for knowing how to most effectively plan out one's goal striving to achieve academic success.

This study represents only a first step in understanding how students can overcome distraction to achieve their academic goals. Future research could examine the impact of task-facilitating versus temptation-inhibiting implementation intentions when learning new rather than well-known cognitive procedures (e.g., algebra), when the distraction is constant rather than intermittent, and when motivation to achieve is high versus low. In addition, future research could examine the plans students spontaneously make to address distraction when it arises (as in Patterson \& Mischel, 1976), and whether self-generated plans have the same outcomes as provided ones.

In sum, the present study shows how thoughtful one must be when planning to protect their academic goal pursuits from distraction. Task-facilitating and temptation-inhibiting plans showed a very different pattern of results, although these two strategies may appear very similar on the surface. However, the ease and practicality of implementation intentions are ideal for the academic environment. and we hope more research will be conducted to examine how implementation intentions can be used in academic settings to improve learning and academic performances.

\section{Acknowledgements}

This material is based upon work supported by a National Science Foundation Graduate Research Fellowship.

\section{References}

Ashcraft, M. H., \& Kirk, E. P. (2001). The relationships among working memory, math anxiety, and performance. Joumal of Experimental Psychology: General. 130 $274-237$.
Baumeister, R. F. $\{1984\}$. Choking under pressure: Self-consciousness and paradoxical effects of incentives on skillful performance. bumol of Personatity ond Social Isychology, 46, 610-620

Beilock, S. L, \& Carr. T. H. (2005). When high-powered people fail: Working memory and "choking under pressure" in math. Psychological science. 16. 101-105.

BrandstätLer, V., Lengfelder, A., Gollwitzer, P. M. (2001). Implementation incention and efficient action initiation. Joutral of Personality and Social Fsychology. 81, $946-960$.

Cool, V. A., Yarborough, D. B., Fatton, J E. Kunde, K., \& Keith, T. Z. (1994). Experimental effects of radio and television distractors on children's performance on mathematics and reading assignments. Joumal of Experimental Edtucition, $62,181-194$.

Deffenbacher. J. L. (1980). Worry and emotionality in test anxiety. In I. G. Sarason (Ed.) Test anxiety: Theory, research, and applications (pp. 111-124). Hillsdale, NJ: Lawrence Erlabaum.

Furst, A. J. \& Hitch, G. J. (2000). Separate roles for executive and phonological components of working memory in mental arthmetic Memory 8 Cogution, 28 $774-782$.

Golwizer, P. M. (1993). Goal achievemen: The mole of intentions. Europem Review of Social Psychology, 4 (pp. 141-185). England: Wiley: Chichester.

Golwizzer, P. M. (1999). Implementation intentions: Strong effects of simple plans. American Psychologist, 54. 493-503.

Golwwizer, P. M. \& Schaal, B. (1998). Metacognition in action: The importance of implementation intentions. Persondity and Social Psycholog Review, 2, 124-136.

Gollwitzer, P. M. \& Sheeran, P. (2006). Implementation intentions and goa achievement: A meta-analysis of effects and processes. Advonces in Experimental Social Pychology, 38, 69-119.

Kane, M. l., Engle, R. W. (2000). Working-memory capacity, proactive interference and divided attention: Limits on long-term memory retrieval. Joumal of Experimental Psychology: Leaning, Memory, and Cognition, 26, 336-358.

Lazarus, R. S. (1999). Stress and emotion: A new synthesis. New York: Springer.

Markow, D. Kim, A., \& Liebman, M. (2007). The MetLife survey of the American teacher: The homework experience. New York, NY: MetLife, inc

Mischel, W. \& Patterson, C I. (1976). Substantive and structural elements of effective plans for self-control fournol of Persondity and Social psychology, 34, 942-950.

Nottelmann, E. D., \& Hill, K. T. (1977). Test anxiety and off-task behavior in evaluative situations. Child Developmint, $48,225 \cdots 231$.

Parks-Stamm, E. J., Gollwitzer, P. M., \& Oettingen, G. (2007). Action control by implementation intentions: Effective cue detection and efficient response initiation. Social Cognition, 25.247-264

Pool M. M. Koolstra, C. M. \& Van der Voort T. H. A. (2003). Distraction effects of background soap operas on homework performance: An experimental study enriched with observational data. Educotional Psychology, $23,361-380$.

Patterson, C. J., \& Mischel, $W$. (1975). Plans to resist distraction. Developmental Psychology, 11. 369-378

Patterson, C J., \& Mischel, W. (1976). Effects of temptation-inbibiting and taskfacilitating plans on self-control. journal of Personality and Sociol Psychology, 33. $209-217$.

Sarason, I. G. (1984). Stress, anxiety, and cognitive interference: Reactions to tests Joumal of Persondity and Social Psychology, 46, 929-938.

Sheeran. P.. Webb, T. L., \& Gollwitzer, P. M. (2005). The interplay between goal intentions and implementation intentions. Personality and Social Psychology Bulletin, 31, 87-98.

Spielberger, C. D. Gonzales, H. P., Taylor, C. I. Anton, E. D. Algaze, B., Ross, G. R., \& Westbery, L. G. (1980). Manual for the Test Anxiery Inventory ("Test Attitude Inventory"). Redwood City, CA: Consulting Psychology Press.

Steele, C. M. (1997). A threat in the air: How stereotypes shape intellectual identity and performance. American Psychologist, 52, 613-629.

Taylor, 1. \& Deanne, F. P. (2002). Development of a short form of the Test Anxiety Inventory (TAI). The foumd of General Psychology, 129, 127-136.

Webb, T S Sheeran P (2003) Can implementation intentions help to overcome egodepletion? foum of Experimentul Socid PSychology, 39, 279-286

Wine, J. D. (1971). Test anxiety and the direction of attention. Psychological Bullerin, 76, $92-104$ 